\title{
Understanding Walking Behavior: Its Benefits and Barriers
}

\author{
Fatmawati \\ Faculty of Medicine and Health, School of Psychology \\ The University of Leeds, United Kingdom \\ fatmawatifadli@rocketmail.com
}

\begin{abstract}
Health survey demonstrates that 5.3 million people each year experienced a premature death due to physical inactivity (Lee et al., 2012). Data from Department of Health (2004) revealed that in the United Kingdom more than $60 \%$ of adult males and $75 \%$ of adult females did not perform enough physical activity. Hence, to minimize this problem, currently, health practitioners are trying to encourage people to be more physically active, especially by promoting several types of exercise, including walking (Marshall et al., 2009; Hallal et al., 2012). Regular walking is one of the essential predictors for long-term physical and mental health benefit. Some recent studies mention that there are lots of advantages if adults can maintain their regular walking (Gunnell, Knuiman, Divitini, \& Cormie, 2014; Morgan, Tobar, \& Synder, 2010; Roe \& Aspinall, 2011; Shiue, 2015; Nagai et al., 2011). Regular walking minimum 10,000 steps each day can burn as much as 400 calories so that it may help overweight or obesity people to reduce their weight (NHS, 2014). However, most of the people perceive walking as one form of transport rather than exercise; therefore, this reason discourages them to walk sufficiently for healthy life purpose (Darker et al., 2007).
\end{abstract}

Keywords: walking, walking benefits, walking barriers

\section{INTRODUCTION}

Health survey demonstrates that 5.3 million people each year experienced a premature death due to physical inactivity (Lee et al., 2012). This is occurred because physical inactivity might increase the risk of non-communicable diseases (NCDs), particularly among individuals who are unable to reach the minimum standard recommended for good health (Graham, Sirard, \&Neumark-Sztainer, 2011; Samuels, Raedeke, Mahar, Karvinen, \& DuBose, 2011; Gilson et al., 2013).

Data from Department of Health (2004) revealed that in the United Kingdom more than $60 \%$ of adult males and $75 \%$ of adult females did not perform enough physical activity. Moreover, the most recent government's physical activity survey in 2013 demonstrated that almost 12.5 million people in England were unable to achieve the minimum requirement of 30 minutes moderate- 
intensity physical activity each week during one month (Sports England, 2013). In Leeds specifically, according to the UK Active data on January 2014, the proportion of physically inactive people were around $26.85 \%$ with some premature death reached 279.5 per 100,000 people, and this spent government budget as much as $£ 17,604,031$ (UK Active, 2014). Hence, to minimize this problem; currently, health practitioners are trying to encourage people to be more physically active, especially by promoting several types of exercise, including walking (Marshall et al., 2009; Hallal et al., 2012).

As it is easily accessible and related to less physical injury compared to other forms of exercise, walking becomes the most favorite physical activity in the world at this time (Freeland, Banerjee, Dannenberg, \&Wendel, 2013). Besides, as broadly known, walking is also free and suitable for people of all ages; even they are not actively engaged in physical activity (Hearst et al., 2013; Sugiyama et al., 2014). These facts are verified by statistical data from studies conducted in the United States and the United Kingdom which reveal that walking has the highest prevalence of all physical activities (Simpson et al., 2003). Furthermore, in several research findings, walking has been identified to be associated with the death reduction from $19 \%$ to $30 \%$, where the most significant reduction was shown by walking $20 \mathrm{~km}$ per week (Woodcock, Franco, Orsini, \& Roberts, 2010).

However, although walking is popular in several countries, its proportion has decreased dramatically. For example, in the United States, the percentage of walking declined from $48 \%$ to 13\% between 1969 and 2009, while in the United Kingdom, its number has fallen from 62\% to 50\% between 1989 and 2004 (Killoran, Doyle, Waller, Wohlgemuth, \& Crombie, 2006).

\section{The Benefits of Walking}

Regular walking is one of the essential predictors for long-term physical and mental health benefit. Some recent studies mention that there are a lots of advantages if adults are able to maintain their regular walking, such as reduce the risk of having cardiovascular disease or some cancers (Gunnell, Knuiman,Divitini, \& Cormie, 2014), improve the mood and emotional stability 
(Morgan, Tobar, \&Synder, 2010; Roe \&Aspinall, 2011; Shiue, 2015), and increase the chances of living longer (Nagai et al., 2011).

It has been acknowledged that walking gives the important preventive influence for some major NCDs, including type-2 diabetes, cardiovascular disease, and back pain (Reid \&Filding, 2012; Savarese et al., 2012; Fritz et al., 2013). In several meta-analyses and systematic reviews, walking has been reported as one of the main contributions in reducing the risk factors for heart disease and stroke, such as improved blood pressure, body mass index, and blood cholesterol level (Semlitsch et al., 2013; Tschentscher, Niederseer, \& Niebauer, 2013; Tudor-Locke et al., 2014). Furthermore, walking is also beneficial for cancer survivors. A survey conducted by health professionals in the United Kingdom suggested that cancer survivors need to maintain their physical activity progressively as the same level as recommended for the general population, and walking seems suitable for them as vigorous-intensity activity may worsen the

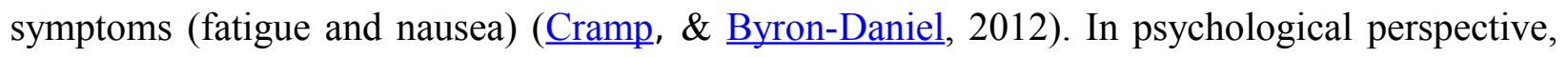
research findings indicated that walking could improve the quality of live by relieving the anxiety and depression symptoms as well as increasing the cognitive performance, such as thinking and understanding (Weuve et al., 2004; Martínez-Gómez et al., 2011).

\section{The Walking Guidelines}

To achieve the minimum standard recommended for good health, physical activity needs to follow the standardized guidelines. These guidelines will describe the appropriate intensity, duration, and frequency that need to be attained by individuals depending on their age and gender (C3 Collaborating for Health, 2012). World Health Organization (2015) divides the physical activity into two forms based on its intensity, namely moderate-intensity and vigorousintensity physical activity. Moderate involves a medium quantity of effort that can quicken the heart rate, while vigorous demands a high level of effort which may accelerate breathing (WHO, 2015). Walking with moderate level includes all walking activities which less than five mph, such as walking for pleasure; whereas walking more than five mph is included to walking with vigorous level, such as race-walking and aerobic walking (Ainsworth et al., 1993). 
Regarding walking, public health recommendations suggest that each person needs to complete 30 minutes moderate-intensity activity (such as brisk walking) on a daily basis (Pate et al., 1995). To make it easily calculated, health practitioners give the guideline which has been translated into step numbers (Tudor-Locke et al., 2011), below is the figure explaining the number of steps that recommended to be achieved per day based on age group.

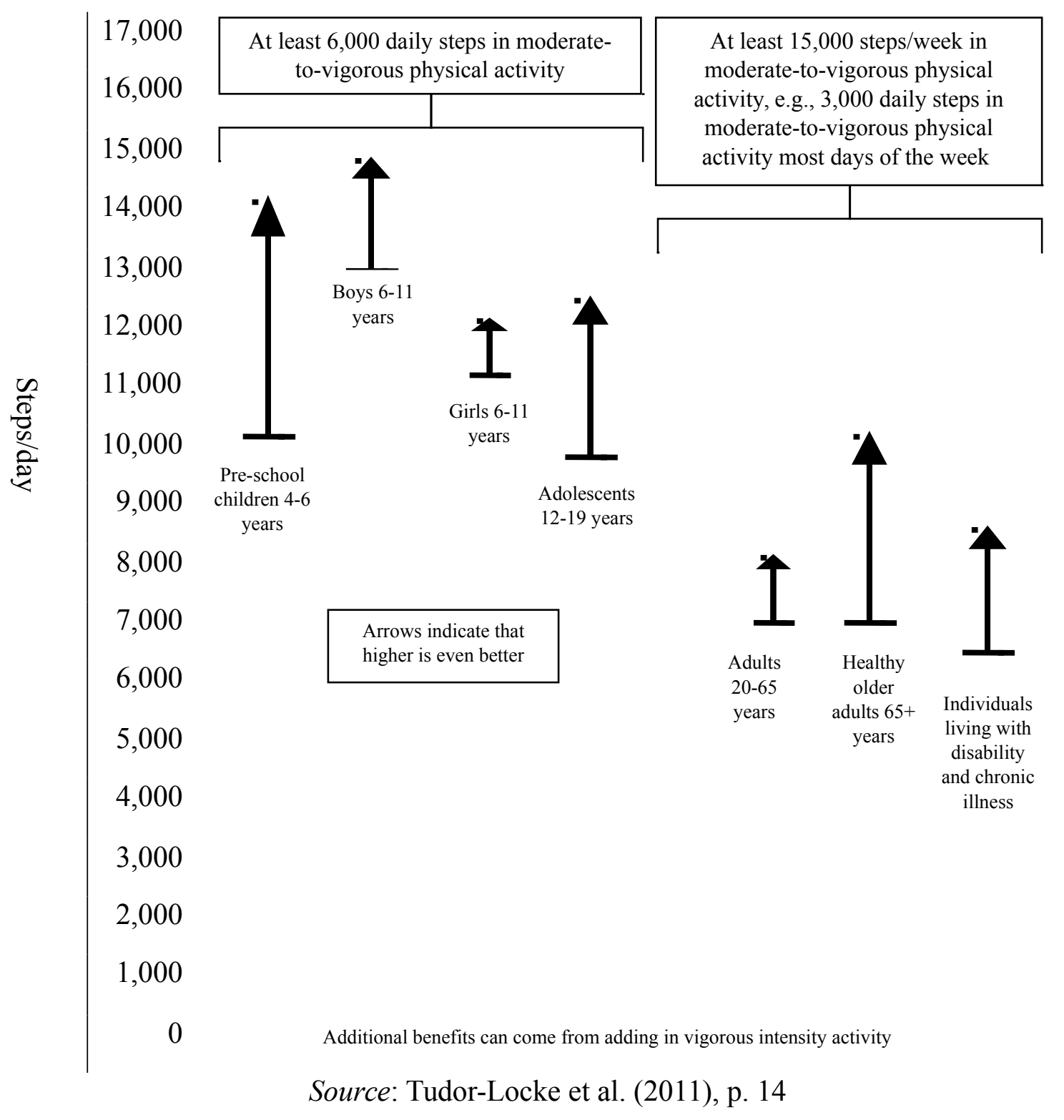

Figure 1. Steps/day scale schematic linked to time spent in moderate-to-vigorous physical activity 
From the figure shown above, adults with age ranged from 20-65 years old are suggested to achieve at least 7,000 steps/day, however, this is the minimum number given which still cannot be categorized as physically active as the benefits of physical activity will be attained if people are active and able to reach more than 10,000 daily steps (Wen et al., 2011). The table below will summarize the categorization for activity level based on steps achieved per day.

Table 1.

Activity Level Category based on Number of Steps

\begin{tabular}{lc}
\hline \multicolumn{1}{c}{ Activity Level } & Number of Steps \\
\hline Sedentary-basal activity & $<2,500$ steps/day \\
Limited activity & $2,500-4,999$ steps/day \\
Low active & $5,000-7,499$ steps/day \\
Somewhat active & $7,500-9,999$ steps/day \\
Active & $10,000-12,499$ steps/day \\
Highly active & $\geq 12,500$ steps/day \\
\hline
\end{tabular}

Source: Tudor-Locke and Bassett (2004), p. 1

As mentioned in the table above, people with active walking level are indicated by 10,000-12,499 steps/day. That is suggested by health professionals to achieve health benefits and improve health outcomes. As mentioned by NHS Choices, for instance, regular walking minimum 10,000 steps each day can burn as much as 400 calories so that it may help overweight or obesity people to reduce their weight (NHS, 2014). Even for normal people, walking within an active level can build stamina and prevent the risk of having NCDs (Samuels et al., 2011).

\section{The Walking Barriers}

Experts suggest that 10,000 are the ideal number of steps that need to be achieved by adults every day (Tudor-Locke et al., 2011). However, most of them fail to comply with this recommendation (Morgan et al., 2010). Even walking is the easiest and most accessible form of physical activity; there are many factors contributing to the barriers to walking, either internal or external factors. Perceived lack of time and lack of an attractive or safe place to walk are two common issues for an extrinsic reason (Duvall, 
2012; Lee at al., 2013); but the intrinsic factor -such as lack of motivation, is the main case to be solved (Geithner, 2011).

According to the research findings discovered by Darker, Larkin, and French (2007), people who walk relatively active each day tend to perceive walking as exercise and stress relief. However, most of the people perceive walking as one form of transport rather than exercise, therefore, this reason discourages them to walk sufficiently for healthy life purpose (Darker et al., 2007). Hence, this negative belief towards walking needs to be altered, especially in developing an effective and successful intervention.

\section{CONCLUSION}

Regular walking is one of the essential predictors for long-term physical and mental health benefit. Some recent studies mention that there are a lots of advantages if adults are able to maintain their regular walking, such as reduce the risk of having cardiovascular disease or some cancers (Gunnell, Knuiman, Divitini, \& Cormie, 2014), improve the mood and emotional stability (Morgan, Tobar, \& Synder, 2010; Roe \& Aspinall, 2011; Shiue, 2015), and increase the chances of living longer (Nagai et al., 2011). People with active walking level are indicated by 10,000-12,499 steps/day. This is suggested by health professionals to achieve health benefits and improve health outcomes. As mentioned by NHS Choices, for instance, regular walking minimum 10,000 steps each day can burn as much as 400 calories so that it may help overweight or obesity people to reduce their weight (NHS, 2014).

\section{REFERENCES}

Ainsworth, B. E., Haskell, W. L., Leon, A. S., Jacobs Jr, D. R., Montoye, H. J., Sallis, J. F., \& Paffenbarger Jr, R. S. (1993). Compendium of physical activities: Classification of energy costs of human physical activities. Medicine and Science in Sports and Exercise, 25(1), 71-80. Retrieved from http://europepmc.org/abstract/med/8292105.

C3 Collaborating for Health. (September, 2012). The benefits of regular walking for health, well-being, and the environment (Review). Retrieved July 21 $1^{\text {st }} 2015$ from http://www.c3health.org/wpcontent/uploads/2009/09/C3-report-on-walking-v-1-20120911.pdf 
Cramp, F., \& Daniel, J. (2008). Exercise for the management of cancer-related fatigue in adults. The Cochrane Library, 2008(2), 1-28. doi: 10.1002/14651858.CD006145.pub2

Darker, C. D., Larkin, M., \& French, D. P. (2007). An exploration of walking behavior: An interpretative phenomenological approach. Social Science and Medicine, 65(10), 2172-2183. doi: 10.1016/j.socscimed.2007.06.029

Department of Health (National Centre for Social Research, Department of Epidemiology and Public Health at the Royal Free and University College Medical School). (2004). Health survey for England 2003: The risk factors for cardiovascular disease (Publication Statistics Vol. 2). London: Stationery Office.

Duvall, J. (2012). A comparison of engagement strategies for encouraging outdoor walking. Journal of Physical Activity and Health,9(1), 62-70. Retrieved from http://www.naspspa.org/AcuCustom/Sitename/Documents/DocumentItem/07_duvduv_JPAH_2009 0338_62-70.pdf

Freeland, A. L., Banerjee, S. N., Dannenberg, A. L., \&Wendel, A. M. (2013). Walking associated with public transit: Moving toward increased physical activity in the United States. American Journal of Public Health, 103(3), 536-542. doi: 10.2105/AJPH.2012.300912

Fritz, T., Caidahl, K., Krook, A., Lundström, P., Mashili, F., Osler, M., ...\&Zierath, J. R. (2013). Effects of Nordic walking on cardiovascular risk factors in overweight individuals with type 2 diabetes, impaired or normal glucose tolerance. Diabetes/metabolism research and reviews, 29(1), 25-32. doi: $10.1002 /$ dmrr.2321

Geithner, C. (Summer 2011). Finding the motivation for exercise and fitness within. American College of Sports Medicine, ACSM Fit Society. 1-8. Retrieved from http://www.acsm.org/docs/fit-societypage/2011summerfspn_behaviorchange.pdf

Gilson, N. D., Faulkner, G., Murphy, M. H., Meyer, M. R. U., Washington, T., Ryde, G. C., ...\& Dillon, K. A. (2013). Walk@work: An automated intervention to increase walking in university employees not achieving 10,000 daily steps. Preventive Medicine, 56(5), 283-287. doi: 10.1016/j.ypmed.2013.01.022

Graham, D. J., Sirard, J. R., \&Neumark-Sztainer, D. (2011). Adolescents' attitudes toward sports, exercise, and fitness predict physical activity 5 and 10 years later. Preventive Medicine, 52(2), 130-132. doi: 10.1016/j.ypmed.2010.11.013

Gunnell, A. S., Knuiman, M. W., Divitini, M. L., \&Cormie, P. (2014). Leisure time physical activity and long-term cardiovascular and cancer outcomes: The busselton health study. European Journal of Epidemiology, 29(11), 851-857. doi: 10.1007/s10654-014-9963-7 
Hallal, P. C., Andersen, L. B., Bull, F. C., Guthold, R., Haskell, W., Ekelund, U., \& Lancet Physical Activity Series Working Group. (2012). Global physical activity levels: Surveillance progress, pitfalls, and prospects. The Lancet, 380(9838), 247-257. doi: http://dx.doi.org/10.1016/S01406736(12)60646-1

Hearst, M. O., Sirard, J. R., Forsyth, A., Parker, E. D., Klein, E. G., Green, C. G., \& Lytle, L. A. (2013). The relationship of area-level sociodemographic characteristics, household composition and individual-level socioeconomic status on walking behaviour among adults. Transportation Research Part A Policy and Practice, 50, 149-157. doi: http://dx.doi.org/10.1016/j.tra.2013.01.006

Killoran, A., Doyle, N., Waller, S., Wohlgemuth, C., \& Crombie, H. (2006). Transport interventions promoting safe cycling and walking: Evidence briefing. London: National Institute for Health and Clinical Excellence.

Lee, I. M., Shiroma, E. J., Lobelo, F., Puska, P., Blair, S. N., Katzmarzyk, P. T., \& Lancet Physical Activity Series Working Group. (2012). Effect of physical inactivity on major noncommunicable diseases worldwide: An analysis of burden of disease and life expectancy. The Lancet, 380(9838), 219-229. doi: 10.1016/S0140-6736(12)61031-9

Lee, P. H., Nan, H., Yu, Y. Y., McDowell, I., Leung, G. M., \& Lam, T. H. (2013). For non-exercising people, the number of steps walked is more strongly associated with health than time spent walking. Journal of Science and Medicine in Sport, 16(3), 227-230. doi: 10.1016/j.jsams.2012.10.005

Marshall, S. J., Levy, S. S., Tudor-Locke, C. E., Kolkhorst, F. W., Wooten, K. M., Ji, M., Macera, C. A., \&Ainsworh, B. E. (2009). Translating physical activity recommendations into a pedometer-based step goal: 3000 steps in 30 minutes. Preventive Medicine, 36(5), 410-killo415. doi: 10.1016/j.amepre.2009.01.021

Martínez-Gómez, D., Ruiz, J. R., Gómez-Martínez, S., Chillón, P., Rey-López, J. P., ainpateDíaz, L. E., ...\& Marcos, A. (2011). Active commuting to school and cognitive performance in adolescents: The AVENA study. Archives of Pediatrics and Adolescent Medicine, 165(4), 300-305. doi: 10.1001/archpediatrics.2010.244

Morgan, A. L., Tobar, D. A., \& Snyder, L. (2010). Walking toward a new me: The impact of prescribed walking 10000 steps/day on physical and psychological well-being. Journal of Physical Activity and Health, 7(3), 299-307. from http://journals.humankinetics.com/AcuCustom/Sitename/Documents/DocumentIteD/18036.pdf

Nagai, M., Kuriyama, S., Kakizaki, M., Ohmori-Matsuda, K., Sone, T., Hozawa, A., ...\& Tsuji, I. (2011). Impact of walking on life expectancy and lifetime medical expenditure: The ohsaki cohort study. BMJ Open, 1(2), 1-7. doi: 10.1136/bmjopen-2011-000240 
Journal of Educational, Health and Community Psychology

Vol 5, No 3, 2016.

Fatmawati

NHS. (2014, 18 ${ }^{\text {th }}$ September). The 10,000 steps challenge. Retrieved August $5^{\text {th }}, 2015$ from http://www.nhs.uk/Livewell/loseweight/Pages/10000stepschallenge.aspx?validate=5\#capturevalidate

Pate, R. R., Pratt, M., Blair, S. N., Haskell, W. L., Macera, C. A., Bouchard, C., ...\& Wilmore, J. H. (1995). Physical activity and public health: A recommendation from the centres for disease control and prevention and the Americantudorcollege of sports medicine. Jama, 273(5), 402-407. doi: 10.1001/jama.1995.03520290054029

Reid, K. F., \& Fielding, R. A. (2012). Skeletal muscle power: A critical determinant of physical functioning in older adults. Exercise and Sport Sciences Reviews, 40(1), 4-12. doi: 10.1097/JES.0b013e31823b5f13

Roe, J., \&Aspinall, P. (2011). The restorative benefits of walking in urban and rural settings in adults with good and poor mental health. Health and Place, 17(1), 103-113. doi: 10.1016/j.healthplace.2010.09.003

Samuels, T. Y., Raedeke, T. D., Mahar, M. T., Karvinen, K. H., \&DuBose, K. D. (2011). A randomized controlled trial of continuous activity, short bouts, and a 10,000 step guideline in inactive adults. Preventive Medicine, 52(2), 120-125. doi: 10.1016/j.ypmed.2010.12.001

Savarese, G., Paolillo, S., Costanzo, P., D'Amore, C., Cecere, M., Losco, T., ...\&Perrone-Filardi, P. (2012). Do changes of 6-minute walk distance predict clinical events in patients with pulmonary arterial hypertension?: A meta-analysis of 22 randomized trials. Journal of the American College of Cardiology, 60(13), 1192-1201. doi: 10.1016/j.jacc.2012.01.083

Semlitsch, T., Jeitler, K., Hemkens, L. G., Horvath, K., Nagele, E., Schuermann, C., ...\&Siebenhofer, A. (2013). Increasing physical activity for the treatment of hypertension: A systematic review and meta-analysis. Sports Medicine, 43(10), 1009-1023. doi:10.1007/s40279-013-0065-6

Shiue, I. (2015). Daily walking $>10$ min could improve mental health in people with historical cardiovascular disease or COPD: Scottish health survey 2012. International Journal of Cardiology, 179, 375-377. doi: http://dx.doi.org/10.1016/j.ijcard.2014.11.058

Simpson, M. E., Serdula, M., Galuska, D. A., Gillespie, C., Donehoo, R., Macera, C., \& Mack, K. (2003). Walking trends among US adults: The behavioural risk factor surveillance system, 1987 2000. American Journal of Preventive Medicine, 25(2), 95-100. doi: 10.1016/S07493797(03)00112-0

Sport England. (2013). Active people survey: Survey 7. Retrieved May 2 ${ }^{\text {nd }}$, 2015 from http://www.sportengland.org/research/active_people_survey/active_people_survey_7.aspx

Sugiyama, T., Cerin, E., Owen, N., Oyeyemi, A. L., Conway, T. L., Van Dyck, D., ...\&Sallis, J. F. (2014). Perceived neighbourhood environmental attributes associated with adults' recreational walking: IPEN adult study in 12 countries. Health and Place, 28, 22-30. doi: 10.1016/j.healthplace.2014.03.003 
Tschentscher, M., Niederseer, D., \&Niebauer, J. (2013). Health benefits of Nordic walking: A systematic review. American Journal of Preventive Medicine, 44(1), 76-84. doi: 10.1016/j.amepre.2012.09.043

Tudor-Locke, C., \& Bassett Jr, D. R. (2004). How many steps/day are enough? Sports Medicine, 34(1), 1-8. doi: 10.2165/00007256-200434010-00001

Tudor-Locke, C., Craig, C. L., Aoyagi, Y., Bell, R. C., Croteau, K. A., De Bourdeaudhuij, I., ... \& Blair, S. N. (2011). How many steps/day are enough? For older adults and special populations. International Journal of Behavioural Nutrition and Physical Activity, 8(1), 80-98. doi: http://www.ijbnpa.org/content/8/1/80

Tudor-Locke, C., Swift, D. L., Schuna, J. M., Dragg, A. T., Davis, A. B., Martin, C. K., ...\& Church, T. S. (2014). WalkMore: A randomized controlled trial of pedometer-based interventions differing on intensity messages. BMC public health, 14(1), 168-174. Retrieved from http://www.biomedcentral.com/1471-2458/14/168

UK Active. (2014, 30 $0^{\text {th }}$ January). Turning the tide of physical inactivity. Retrieved August $2^{\text {nd }}, 2015$ from http://ukactive.com/downloads/managed/Turning_the_tide_of_inactivity.pdf

Wen, C. P., Wai, J. P. M., Tsai, M. K., Yang, Y. C., Cheng, T. Y. D., Lee, M. C., ... \& Wu, X. (2011). Minimum amount of physical activity for reduced mortality and extended life expectancy: A prospective cohort study. The Lancet, 378(9798), 1244-1253. doi: 10.1016/S0140-6736(11)607496

Weuve, J., Kang, J. H., Manson, J. E., Breteler, M. M., Ware, J. H., \&Grodstein, F. (2004). Physical activity, including walking, and cognitive function in older women. Jama, 292(12), 1454-1461. doi: $10.1001 /$ jama.292.12.1454

Woodcock. J., Franco, O.H., Orsini, N., \& Roberts, I. (2010). Non-vigorous physical activity and allcause mortality: Systematic review and meta-analysis of cohort studies. International Journal of Epidemiology, 40, 121-138. doi: 10.1093/ije/dyq104

World Health Organization. (2015). What is moderate-intensity and vigorous-intensity physical activity? Retrieved May $20^{\text {th }}, 2015$ from http://www.who.int/dietphysicalactivity/physical_activity_intensity/en/ 